\title{
Estudio de la presencia de la Teología Católica en las Universidades Públicas Españolas en la primera década del siglo XXI"
}

\author{
Rafael González Martín
}

Recibido: 12 de octubre de 2016 • Aprobado: 3 de diciembre de 2016

\section{Resumen}

Como consecuencia de la salida de la teología de las universidades civiles españolas en 1853, los estudios teológicos se vieron refugiados en los seminarios diocesanos alcanzando estos la facultad de otorgar el grado de bachiller, licenciado y doctorado en Teología. La Iglesia española desde 1853 hasta los preludios del Concilio Vaticano II (CV II), vivió de esta estructura.

Es a partir del CV.II y de la separación de la religión del carácter oficial del estado, cuando se comienza un nuevo florecimiento y expansión de las facultades y centros de estudios teológicos, desarrollando estos en la primera década del siglo XXI un gran avance investigador del pensamiento teológico, dando lugar a una nueva presencia de la Teología en las Universidades Públicas Españolas.

El presente artículo presenta las distintas formas de presencia en el marco de la Universidades Públicas Españolas.

Palabras Claves: Teología, Universidad Pública, Centros Teológicos, Humanidades

Trabajo realizado dentro del programa de Doctorado en Teología de la Universidad de Murcia en colaboración con el Instituto Teológico de Murcia OFM en la línea de investigación: Visión del hombre y el mundo desde la perspectiva cristiana perteneciente al Departamento de filosofía y sociedad y Religión y Cultura, conducente a la Tesis Doctoral: "Estudio de la presencia de la Teología en las Universidades Públicas en los albores del siglo XXI" (2016). Universidad de Murcia-Instituto Teológico de Murcia.

** Profesor en el Colegio María Auxiliadora. Salesianas. Écija. Instituto Teológico de Murcia-Universidad de Murcia. Email: r.gonzalezm@hotmail.com. 


\title{
Study of the presence of Catholic theology in the Spanish Public Universities in the first decade of the century
}

\begin{abstract}
Following the departure of the theology of the Spanish civil universities in 1853, the refugees were theological studies in the diocesan seminaries reaching these the power to grant a bachelor's degree, graduate and doctorate in theology. The Spanish Church from 1853 to the preludes of Vatican II (CV II), lived in this structure.

It is from CV.II and separation of religion from the official character of the state, when a new flourishing and expansion of the faculties and centers of theological studies begin developing these in the first decade of the century a great researcher advance theological thinking, resulting in a new presence of Theology in Spanish public universities.

This article presents the different forms of presence within the Spanish public universities.

Keywords: Theology, Public University, theological centers, Humanities
\end{abstract}

\section{Étude de la présence de la théologie catholique dans les universités publiques espagnoles pendant la première décennie du XXI siècle}

\section{Résumé}

Comme conséquence de la sortie de la théologie des universités civiles espagnoles en 1853, les études théologiques se sont vues reléguées aux séminaires diocésains atteignant le pouvoir d'accorder le diplôme du baccalauréat, la licence et doctorat en théologie. L'Église espagnole vécu de cette structure depuis 1853 jusqu'aux préludes du Concile Vatican II (CV II). C'est à partir du CV II et de la séparation de la religion du caractère officiel de l'État, que commence une renaissance et une croissance des facultés et des centres d'études théologiques, permettant de réaliser un grand pas dans la recherche de la pensée théologique pendant la première décennie du XXI siècle, et conduisant à une nouvelle présence de la théologie dans les universités publiques espagnoles.

Cet article présente les différentes formes de présence dans le cadre des universités publiques espagnoles.

Mots clés: Théologie, université publiques, centres théologiques, sciences humaines. 


\section{Introducción}

Es un hecho que la Teología hoy está presente en muchas universidades públicas o estatales del mundo (sobre todo en Estados Unidos y Alemania), donde prestigiosas facultades de teología ocupan un lugar natural en el concierto de los saberes universitarios.

En cambio, la relación entre la Teología y el mundo universitario estatal quedó interrumpida en España, en virtud del conocido "Decreto de Libertad de Enseñanza", de 21 de octubre de 1868, en el que las Facultades de Teología fueron abolidas y, en consecuencia, excluidas de la enseñanza universitaria pública en España. Desde entonces el diálogo y el trabajo interdisciplinar entre la Teología y los demás saberes universitarios han sido prácticamente inexistentes en el seno de las universidades públicas españolas. Mención aparte de la enseñanza de Teología católica y pedagogía religiosa que se ha impartido en las Escuelas de Magisterio y, hoy en día, en las Facultades de Educación dentro de los Grados de Maestro.

Esto no quiere decir que el hecho religioso y los saberes asociados a él hayan estado ausentes de las universidades públicas. El fenómeno religioso siempre ha estado y sigue estando presente en el tejido social de España; por lo que ha sido objeto de estudio en la enseñanza universitaria desde no pocos puntos de vista: la cultura, la historia, la política, la sociología, el arte, la psicología y tantos otros saberes que quedan inevitablemente incompletos si de ellos arrancamos la dimensión religiosa que siempre, de una forma o de otra, ha estado y está presente en la experiencia humana y en la convivencia social. Lógicamente desde este punto de vista, al parecer, la Teología forma parte de la universidad pública como disciplina que analiza nuestra historia cultural, los fenómenos religiosos y como parte de la psicología, la sociología o la antropología.

El presente trabajo ha tenido como objeto estudiar la nueva presencia de la Teología Católica en las Universidades Públicas Españolas. Y, si esa presencia se constituye como disciplina propia, con materias propias, y lógicamente con reconocimiento de titulación universitaria dentro del marco de la Universidad pública.

El estudio confirma que es en la década de los noventa del siglo XX y especialmente en la primera década del presente siglo cuando la teología está teniendo un nuevo reencuentro con las Universidades públicas Españolas, abriéndose en ellas, cauces para una nueva presencia de la teología en su seno. Esta presencia de la Teología en las universidades públicas está justificada y revisada en nuestro trabajo, bajo el amparo de la Ley Orgánica 6/2001 de diciembre, de Universidades (BOE n. 307 de 24/12/01) modificada por la Ley Orgánica 4/2007, de 12 de abril 
(BOE n. 99 de 13/04/2007), que establece en los apartados c) y j) del artículo 2, la autonomía de las Universidades en función de la cual, regular la posibilidad de creación de estructuras específicas que actúen como soporte de la investigación y la docencia.

\section{Presencia de la Teología Católica en las Universidades Públicas Españolas}

En la actualidad, la presencia de la Teología Católica en las Universidades Públicas Españolas, independientemente de la enseñanza de Teología católica y pedagogía religiosa que se imparte en las Facultades de Educación dentro de los Grados de Maestro para el reconocimiento de la Declaración de Idoneidad para la enseñanza religiosa en los niveles de la enseñanza infantil y primaria, viene marcada por dos presencias muy significativa. Una de ella viene a través de la creación de una Cátedra de Teológica dentro del marco universitario (Cátedra de Teología-Universidad de Granada; Cátedra de las Tres Religiones-Universidad de Valencia; Cátedra de Teología y Ciencias de la Religión “Ignacio Ellacuría”Universidad Carlos III de Madrid), cuyo fin es buscar la ocasión a que la teología ofrezca su peculiar luz de conocimiento, partiendo del convencimiento de que los elementos más significativos de la tradición religiosa generan sentido y propuestas que pueden entrar en diálogo honesto con otras disciplinas.

La otra presencia es más significativa y viene establecida por la Universidad de Murcia, pues en ella, se reconoce a la Teología como una disciplina propia, con materia propia y como consecuencia otorgándose por la universidad a dicho reconocimiento académico una titulación oficial.

\section{Universidad de Murcia. Máster en Teología y un Programa de Doctorado en Teología.}

Teniendo en cuenta lo anteriormente expuesto, se analiza a continuación, la presencia de la Teología dentro del marco de la Universidad de Murcia con su programa de Máster Oficial Universitario en Teología y el Doctorado en Teología.

Los estudios de postgrado en Teología tienen la intención de insertar en el ámbito universitario civil los estudios teológicos teniendo en consideración las distintas aportaciones e interrelaciones de los dos espacios del saber hasta ahora demasiado alejados. El Máster pretende una formación integral de los futuros 
postgraduados y atiende tanto a la formación investigadora y a la docente como a otra más importante aún en estos tiempos: la formación integral del postgraduado, a nivel humano, científico y ético.

El Máster Universitario en Teología, que se propone, posee una relevancia propia dentro del campo teológico, especialmente en el ámbito de la especialización en el estudio y la investigación teológica, debido a la programación pensada para ofrecer a los estudiantes una formación específica en el estudio de la teología. Supone la profundización en la formación ya recibida en el Grado.

De esta manera, se cree que el Máster puede dar un sentido concreto a los estudios de teología en el mundo de hoy. Se trata de fijar las posiciones que la teología tiene y debe aportar al diálogo multidisciplinar en un mundo en constante evolución. Por ello se hace necesario un Máster que permita a los estudios de teología ampliar su horizonte con el fin de ser más fieles a su misión, que no es otra que el servicio al Magisterio eclesial con el fin de «dar siempre razón de nuestra esperanza» (1 Pe 3, 15), para que el mundo crea y se salve por la fe en Jesucristo, Redentor del hombre. Seguimos en esto las orientaciones del Concilio Vaticano II en su Decreto Optatam Totius 16: "Las disciplinas teológicas han de enseñarse a la luz de la fe y bajo la guía del magisterio de la Iglesia, de modo que los alumnos deduzcan cuidadosamente la doctrina católica de la Divina Revelación; penetren en ella profundamente, la conviertan en alimento de la propia vida espiritual, y puedan en su vida anunciarla, exponerla y defenderla. Fórmense con diligencia especial los alumnos en el estudio de la Sagrada Escritura, que debe ser como el alma de toda la teología; una vez antepuesta una introducción conveniente, iníciense con cuidado en el método de la exégesis, estudien los temas más importantes de la Divina Revelación, y en la lectura diaria y en la meditación de las Sagradas Escrituras reciban su estímulo y su alimento".

Además se tiene presente las orientaciones constantes del Magisterio para que la teología tenga una vertiente ecuménica clara y una perspectiva de diálogo con las otras religiones y con el mundo moderno (Cf., Unitatis Redintegratio 10).

Asimismo, se ha tenido presente lo que el artículo 40 de Sapientia Christiana propone como adecuado para la formación teológica, de modo que se observe un método progresivo de aprendizaje de la teología para alcanzar la madurez científica: “ a) se ofrezca en primer lugar una información general, mediante la exposición coordinada de todas las disciplinas, junto con la introducción al uso del método científico (propio del Grado); b) sucesivamente se aborde con mayor profundidad el estudio de un sector particular de las disciplinas y al mismo tiempo se ejercite más de lleno a los alumnos en el uso del método de investigación 
científica; c) finalmente, se vaya llegando progresivamente a la madurez científica, en particular mediante la elaboración de un trabajo escrito, que contribuya efectivamente al adelanto de la ciencia". Los puntos b y c son los que se aplican al Máster Universitario en Teología.

El Máster propuesto tiende a la formación académica holística de los licenciados o graduados en humanidades. El objetivo es el aprovechamiento de los estudios de teología como rama del saber que permite una profundización en la historia de las ideas, la hermenéutica de los textos, el diálogo en un mundo plural y la puesta en acción de las técnicas para asumir y comprender una realidad global, compleja y plural. Esta visión integradora de las ciencias se ha abierto camino desde hace unos decenios en las universidades del ámbito americano. Allí, los Estudios Culturales persiguen romper la atomización del saber que se estaba produciendo por el excesivo empeño utilitarista en las ciencias humanas, derivado del utilitarismo economicista que imperaba en el ambiente académico. Mediante la integración de la Literatura, los estudios sociales, las distintas artes, especialmente el cine, la antropología cultural y social y la economía política, se pretende dar una perspectiva integradora que comprenda al hombre en su mundo. Hoy debemos encaminarnos también a esta concepción. Lo vemos en la unificación de los estudios de Doctorado en Humanidades, que integran lo que fueron distintos doctorados. En la actualidad hay veintitrés líneas de investigación para un solo título de Doctor en Humanidades en la Universidad de Murcia y la integración va en aumento, por eso mismo la Teología, como disciplina y como rama del saber humano, puede y debe aportar su experiencia de siglos, como ha quedad visto arriba, y su perspectiva global de la realidad humana.

El Máster es el resultado de muchos años de experiencia docente e investigadora del Instituto Teológico de Murcia OFM, que ha dado como resultado la formación de buenos profesionales de la enseñanza y la investigación académica. Desde la incorporación del Instituto Teológico a la Facultad de Teología Fundamental de la Universidad Pontificia Antonianum de Roma. Esta asociación permite que el Instituto pueda disfrutar de la presencia de una amplia variedad de estudiantes de distintas nacionalidades y ámbitos de estudio e investigación, creando un ambiente plural e internacional en las aulas y entre el cuerpo de docentes. Esta experiencia puede suponer un plus investigador y docente y aportar el caldo de cultivo de lo que la teología quiere ser hoy en el mundo académico y científico: el punto de encuentro de diversas posturas; la unidad en medio de la diversidad; la armonía de lo heterogéneo; la cohesión en la complejidad; el vínculo de todas las posturas que florecen en este mundo global y en crisis. 
El Máster Universitario en Teología por la Universidad de Murcia, ha sido aprobado por Agencia Nacional de Evaluación de la Calidad y Acreditación (ANECA), teniendo carácter pionero: no hay otro de similares características en España y tampoco en el ámbito de estudios superiores europeo (excepción hecha de Alemania). Este carácter innovador impide poder evidenciar referencias explícitas tanto nacionales como internacionales de un Máster Universitario en Teología en Facultades Civiles. Sí que existen los referentes de Facultades de Teología Eclesiásticas que están realizando másteres específicos de alguna de las ramas de los estudios teológicos: Máster en Discernimiento Vocacional y Acompañamiento Espiritual de la Universidad Pontificia de Comillas, Máster en Teología Ecuménica y Diálogo Interreligioso de la Universidad Pontificia de Salamanca, y Máster en Formación de la Universidad Pontificia Antonianum de Roma.

En el ámbito propio de la Teología, la realización del Máster Universitario en Teología debe servir para que cualquiera que lo curse sea capaz de apreciar el potencial de la Teológica para hacerse cargo de uno de los rasgos más característico de las sociedades multiculturales y multirreligiosas de nuestra época: el hecho de conceder un papel relevante a las "estructuras de sentido" como es el caso de la religión, hasta el punto de que las religiones han cobrado una relevancia insospechada hace unas décadas en nuestras sociedades.

La Teología puede aportar, tanto en sí misma como en las conexiones que establece con otros espacios del saber. En sí misma, porque los propios estudios de Teología en el Máster incluyen un abanico impresionante de formación: metodología, hermenéutica, historia, arte, filosofía, ciencias naturales, ciencias sociales, literatura, fenomenología, religiones, secularización, estudios culturales...; en las conexiones con otros espacios del saber, porque hoy día la Teología es el saber integrador por excelencia. Basta repasar cualquier elenco de publicaciones teológicas para constatar la pluralidad y diversidad de las mismas en su intento de establecer un diálogo fructífero con todos los campos de conocimiento. Puede verse el número ingente de publicaciones en torno a la teología y la ciencia, la teología y las distintas ramas de la antropología, la teología y la literatura, la teología y el mundo antiguo, la teología y la historia, la teología y la filosofía, la teología y el arte y la cultura actual.

Todo esto lleva a creer que la existencia de un Máster Universitario en Teología (especialmente si se hace desde una Universidad Civil, caso único en el ámbito de estudios superiores, sólo en las universidades alemanas la Teología es una más de las ciencias), está sobradamente justificado como modo de volver al origen de lo que fue el nacimiento de los estudios universitarios, recuperando de 
alguna manera el sentido y valor etimológico de la universitas. Pero también está justificado como forma de mirar al futuro, un futuro que exige nuevas maneras de integración de la multiplicidad en todos los ámbitos, también en el académico. De alguna manera, esto es lo que siempre ha hecho la Teología: enraizarse en la tradición como medio más eficaz de poder dar frutos en el presente y abrir la esperanza en el futuro, porque su ser es un ser en el tiempo, pero un tiempo cargado de esperanza.

Esta propuesta de título oficial de máster por la UM tiene su principal referente de adecuación en la legislación vigente preceptiva en el territorio nacional. El marco regulador justificativo de la propuesta aquí presentada está, así pues, constituido básicamente por la siguiente normativa estatal:

Máster Universitario en Teología.

- $\quad$ Real Decreto 1125/2003, de 5 de septiembre, por el que se establece el sistema europeo de créditos y el sistema de calificaciones en las titulaciones universitarias de carácter oficial y validez en todo el territorio nacional (BOE de 18/9/03).

- $\quad$ Real Decreto 1393/2007, de 29 de octubre, por el que se establece la ordenación de las enseñanzas universitarias oficiales (BOE de 30/10/07) Particular interés para la elaboración de esta propuesta tienen los principios generales a que hace referencia su artículo 3.5.

Para la elaboración de esta propuesta de Máster Universitario en Teología se cotejó las propuestas de similares características, salvando el hecho de que este sería el primer Máster Universitario en Teología de una universidad civil, en centros nacionales e internacionales como:

- Universidad Pontificia Comillas: Máster en Discernimiento Vocacional y Acompañamiento Espiritual.

- Universidad Pontificia de Salamanca: Máster en Teología Ecuménica y Diálogo Interreligioso.

- Pontificia Universidad Antonianum: Máster en Formación.

- Pontificia Universidad Salesianum: Máster responsabili e coordinatori di oratorio.

Para la elaboración del plan de estudios se siguieron tanto el reglamento de la Universidad de Murcia para la aprobación de un Máster, es decir, aprobación en los departamentos de la participación de los profesores implicados, aprobación en las juntas u órganos de gobierno de los centros implicados, aprobación en la Comisión de Estudios de Máster del Consejo de Gobierno y, en último término, aprobación por el propio Consejo de Gobierno de la Universidad de Murcia; como la consulta de los órganos internos de gestión del Instituto Teológico de 
Murcia OFM que están establecidos en los Estatutos de dicho centro: Consejo de Gestión, según los artículos 14-16; Consejo de Instituto, según los artículos 20-22; Consejo de Presidencia, según los artículos 23-25; Departamentos de Teología y Filosofía.

En relación a los procedimientos de consulta internos utilizados para la elaboración y diseño de este programa de postgrado se destacaron:

- La oferta para el título del Máster fue elaborada por el Consejo de Presidencia a instancias del Consejo de Instituto y del Consejo de Gestión del Instituto Teológico de Murcia OFM.

- Propuestas de profesores, a través de los Departamentos de Teología y Filosofía para la elaboración de las distintas materias y asignaturas.

- Aprobación por el Consejo de Instituto.

- Reglamento por el que se regulan los estudios de Postgrado de la Universidad de Murcia, documentos, normativas e información procedente de esta Universidad, así como consultas específicas con La Vicerrectora de Estudios y /o la Coordinadora de Postgrado.

A partir de las estancias trimestrales de la Dirección del centro en Roma y su contacto con los directores de otros centros universitarios, se fue creando la conciencia de la necesidad de integrar mejor los estudios teológicos en el ámbito universitario civil, con el fin de hacer presente la teología en la sociedad y la sociedad en la misma teología, deviniendo una relación de enriquecimiento mutuo.

Asimismo, la relación establecida entre el Instituto Teológico de Murcia OFM, en especial, con las Facultades de Educación y Letras, especialmente Arte, han generado la necesidad de fomentar los vínculos existentes ofertando la posibilidad de un Máster Universitario en Teología para los alumnos de la Universidad de Murcia.

Se ha procedido a la consulta de otros centros externos para la elaboración del plan de estudios. Estos centros son la referencia inmediata del Instituto Teológico de Murcia OFM para la elaboración de sus estudios:

- Pontificia Universidad Antonianum de Roma

- Pontificia Universidad Salesianum de Roma

- $\quad$ Facultad de Educación de la Universidad de Murcia

- $\quad$ Facultad de Letras de la Universidad de Murcia

También se realizó un proceso de consulta en distintas reuniones con profesionales en ejercicio o egresados que manifestaron la utilidad que un Máster de estas características podría aportar a la sociedad. Se recabó la opinión de: los alumnos del Instituto Teológico de Murcia, la Asociación de Antiguos Alumnos, profesores de la Universidad de Murcia que imparten docencia en este centro 
o que tienen relación con él, los alumnos del máster que este centro imparte: "Guía y Mantenimiento de los Bienes culturales de la Iglesia", a los miembros de SAFAMUR (Centro de Orientación y Mediación Familiar) y a la Fundación Acción Franciscana.

- Máster Oficial Universitario en Teología. (Presencial y online).

- Los estudios del Máster Oficial Universitario en Teología, cumpliendo con el R.D 1393/2007, de 29 de octubre de 2007, que establece la ordenación de las enseñanzas universitarias oficiales y con el Reglamento por el que se regulan los Estudios Universitarios Oficiales de Máster y Doctorado de la Universidad de Murcia, el Plan de Estudios de Máster Oficial Universitario en Teología se organiza según el Sistema Europeo de Transferencia de Créditos (ECTS). Constará de 60 Créditos de 25 horas de duración cada uno a impartir a lo largo de un curso académico (dos cuatrimestres).

- La organización se realiza en tres bloques formativos bien diferenciados:

- Bloque formativo A: Se pretende que el alumno adquiera la formación básica en los rudimentos de la teología, sobre todo a nivel metodológico, hermenéutico y de fundamentación de los pilares esenciales de la teología.

- Bloque formativo B: Con este bloque formativo se busca que el alumno personalice la formación que le conduce a la investigación y a la docencia.

- $\quad$ Bloque formativo C: Este último bloque formativo está orientado a la práctica investigadora. El alumno deberá demostrar haber adquirido todas las competencias de la titulación, mediante un trabajo de investigación original y dirigida, que concluye con la elaboración de Trabajo Fin de Máster, su presentación y defensa.

\section{Programa de Doctorado de Teología.}

Se trata de un Programa de Doctorado unitario que comprende la formación de doctores relacionada con las Bellas Artes, la Teología y las Lenguas Clásicas y Modernas. Es un doctorado, por lo tanto, muy amplio y diverso, que ofrece posibilidades muy variadas y plurales para todos los que quieran acercarse a la investigación en esta rama de conocimiento y para quienes persigan un enfoque interdisciplinar en el ámbito de las Artes y Humanidades. 
La línea de investigación en Teología pretende que los doctorandos realicen una aplicación de los conocimientos adquiridos en el ámbito de las ciencias humanas a la investigación teológica, de modo que los expresen con claridad, e integren los campos del pensamiento propios de las Artes y Humanidades a la reflexión teológica, dentro de un diálogo fecundo y recíproco. Asimismo, se busca la integración de la Teología en el mundo de la investigación académica normalizada, tal como fue desde el inicio de esta rama del saber.

\section{Universidad de Granada. Cátedra de Teología.}

Esta Cátedra es una iniciativa conjunta de la Universidad de Granada y de la Facultad de Teología regentada por los jesuitas, que se lleva a cabo en el marco del Convenio vigente entre ambas instituciones, firmado hace ahora 40 años (con ocasión de la venta de la finca de Cartuja para campus universitario).

Lo que se pretende con esta Cátedra es dar ocasión a que la teología ofrezca su peculiar luz de conocimiento, partiendo del convencimiento de que los elementos más significativos de la tradición religiosa generan sentido y propuestas que pueden entrar en diálogo honesto con otras disciplinas.

La Cátedra de Teología de la Universidad de Granada está en la línea de otras iniciativas semejantes en universidades públicas españolas, por no hablar de tantas universidades europeas donde la teología es una facultad universitaria más.

Objetivos:

- Ofrecer un espacio de reflexión permanente, en el seno mismo de la Universidad de Granada, sobre la aportación específica de la tradición cristiana y de otras tradiciones religiosas a la configuración de nuestro mundo.

- Reflexionar sobre los temas fundamentales que configuran la existencia humana, desde una perspectiva interdisciplinar y en diálogo con otros saberes científicos.

- Colaborar, a través del diálogo, con las distintas religiones para la construcción de una convivencia pacífica.

Para hacer realidad estos fines se desarrollarán actividades como las que siguen:

- Acciones docentes e investigadoras. La docencia se desarrollará mediante seminarios, cursos, conferencias, etc. La investigación se realizará mediante la creación de un grupo interdisciplinar de investigación.

- Creación de un seminario permanente con profesoras/es, personal de administración y servicios, y estudiantes de distintas especialidades, 
con la finalidad de tratar la aportación específica de las religiones a los problemas fundamentales antes mencionados.

- Organización de seminarios y cursos, en las áreas específicas del saber teológico, destinados a estudiantes de la Universidad, pudiendo ser reconocidos por la Universidad, como créditos en sus titulaciones, conforme a su normativa.

- Celebración de un Congreso bianual en que el que se puedan ofrecer los aportes más novedosos y significativos de la teología actual.

- Publicación de artículos, actas de congresos, etc. para el enriquecimiento de la actividad docente y el incentivo de la investigación.

\section{Universidad de Valencia. Cátedra de las Tres Religiones.}

La junta de gobierno de la Universidad de Valencia aprobó a finales de 1999 la creación de la cátedra de las Tres Religiones, dedicada a la investigación, la docencia y la difusión de la función social y cultural de las tres grandes religiones monoteístas del Mediterráneo -la islámica, la judaica y la cristiana-. El interés y la necesidad de crear una cátedra dedicada al estudio de estas tres religiones surgieron, en el marco del congreso celebrado dentro de la conmemoración de Cinc Segles de la Universidad, que reunió en Valencia a especialistas de estas confesiones.

La cátedra se articulará a través de un convenio de la Universidad con la Federación de Comunidades Israelitas y la Unión de Comunidades Islámicas, ambas con sede en España, y el Centro Ecuménico Padre Congar, adscrito a la orden dominica.

La nueva cátedra organiza cursos sobre las grandes religiones para licenciados y estudiantes de la Universidad de Valencia dentro de la opción de créditos de libre elección; así como conferencias, seminarios y la publicación de obras clásicas de autores islámicos, judíos y cristianos, y todos aquellos trabajos de investigación relacionados con las tres culturas que surjan de la propia cátedra como de la colaboración con centros internacionales especializados.

La financiación de la cátedra provendrá de fondos compartidos por las instituciones que la impulsan, y del porcentaje de tasas de matrículas de los cursos y masters de postgrado sobre estas materias.

La Cátedra sigue ofertando cursos para la obtención de créditos de libre elección. 
La Cátedra se compromete a participar y colaborar con otras entidades culturales para hacer realidad la reflexión e investigación de hechos políticos, sociales y culturales que a todos nos afectan.

En el espíritu, de la Cátedra hay tres conceptos que aparecen constantemente y que, sin duda, son significativos: Cultura, Religión y Diálogo. Son conceptos que invitan a levantar la vista; que no permiten el quedarse parado, sentado sobre la piedra del conformismo y de la resignación; que no soportan los prejuicios; que miran al otro como aquel que puede aportar otras ideas, otras experiencias, otra realidad, otra expresión... Son posibilidades: La Religión es una posibilidad; la Cultura es una posibilidad; el Diálogo es una posibilidad. Cultura, Religión y Diálogo, nos presentan caminos nuevos, horizontes de luz, que invitan a encontrarnos, a compartir, a crecer, a vivir.

La religión ha sobrevivido a los augures de su muerte y a los profetas de su desaparición. Y hace pensar no solamente porque plantea cuestiones clave de la existencia, sino por- que es una dimensión del ser humano que está ahí dentro. El gran reto de las religiones, en este contexto, es siempre el intercambio enriquecedor y éste, desde su enorme diversidad, dando lo mejor de sí mismas, ofreciendo gratuitamente su revelación, sin imponer de forma coercitiva sus proyectos, sus sistemas, sus dogmas

\section{Universidad Carlos III de Madrid. Cátedra de Teología y Ciencias de la Religión “Ignacio Ellacuría”.}

En el año 2001 y dentro del seno de la Universidad Carlos III de Madrid y bajo la dirección del filósofo y teólogo Juan José Tamayo y bajo la financiación Fundación Carlos III de Madrid vinculada con el Instituto de Derechos Humanos Bartolomé de Las Casas y Universidad Carlos III de Madrid nace la Cátedra de Teología y Ciencias de la Religión "Ignacio Ellacuría”.

Objetivos de la Cátedra:

- Crear un espacio de reflexión permanente, sobre las religiones, su relevancia histórica y su significación cultural, en perspectiva interdisciplinar y en diálogo con los distintos saberes universitarios.

- Posibilitar espacios de diálogo interreligioso e intercultural como alternativa a las guerras de religiones, que vuelven a resurgir, y al choque de civilizaciones, que se tiende a presentar como ley de la historia.

- Ofrecer a los estudiantes universitarios y a los ciudadanos interesados una visión de conjunto de las grandes religiones del mundo en su historia y en el momento actual. 
- Introducir a los estudiantes en la metodología de las Ciencias de las Religiones.

- Aproximar al mundo universitario al estudio del fenómeno religioso en toda su complejidad, riqueza y ambigüedad, a partir de las distintas disciplinas que lo estudian: historia de las religiones, filosofía de la religión, sociología de la religión, fenomenología de la religión, psicología de la religión, antropología de la religión, ecología de la religión, teología de las religiones, etc.

- Promover el estudio de los textos religiosos en la doble clave filológica y hermenéutica, en el contexto en que surgen y en sus desarrollos ulteriores, y analizar la influencia ejercida en las distintas manifestaciones culturales.

- Estudiar las religiones en su dimensión antropológica y cultural.

- Estudiar las religiones desde la perspectiva de género.

- Analizar las religiones en su perspectiva y funcionalidad política, social, económica y cultural, y en sus relaciones con el poder.

- Ofrecer un análisis de la crítica moderna y postmoderna de la religión a través de sus principales pensadores y de sus más notables manifestaciones.

- Estudiar la crisis cultural de las religiones en la modernidad, así como el actual despertar religioso en sus variadas formas: desde el fundamentalismo hasta el diálogo interreligioso, y en su funcionalidad ideológica y sociopolítica.

- Posibilitar espacios de investigación y estudio sobre el cristianismo en sus orígenes, en su evolución histórica y en la crisis actual, en diálogo con la cultura moderna y posmoderna.

Temas de reflexión, estudio, investigación y docencia:

Viaje por las grandes religiones del mundo: visión histórica y problemática actual; conceptos fundamentales de cada religión; fundadores; dioses y diosas; lugares sagrados; tiempos sagrados; textos sagrados; personas sagradas; acciones sagradas, etc.

Derecho y Religión. Ciencias Sociales y Religión. Economía y Economía. Política y Religión. Arte, Estética y Religión. Globalización y Religión. Secularización y Religión. Culturas y Religiones. Ética y Religión. Derechos Humanos y Religiones. Violencia y Religiones. Ética civil y Ética religiosa. Sociedad y Religión. Minorías religiosas. Bioética y Religión. Biogenética y Religión. Ecología y Religión. Religiones, Interculturalidad y Comunidad internacional. Religión y Género. Diálogo interreligioso. El fenómeno del fundamentalismo en las religiones monoteístas: 
judaísmo, cristianismo, Islam. Aportación de las religiones a una ética universal. Identidad y funciones de las religiones en las sociedades democráticas. La mujer en las grandes religiones monoteístas: judaísmo, cristianismo, islam. Estudio diacrónico y sincrónico.

Paradigmas del cristianismo en la historia: a) el paradigma judeo-cristiano de los orígenes; b) el paradigma helenista universalista; c) el paradigma católico romano- medieval; d) El paradigma de la Reforma; e) El paradigma de la Modernidad; f) El paradigma de la liberación; d) el paradigma del diálogo inter-religioso.

Corrientes teológicas actuales: teología hermenéutica, teología existencial, teología de la secularización, teología política, teologías de la liberación, teología del diálogo interreligioso.

Confesiones cristianas: Iglesia Ortodoxa, Protestantismo, Anglicanismo, Catolicismo.

El cristianismo en la construcción de Europa: pasado, presente y futuro.

Modalidades y campos de trabajo de la Cátedra:

- Investigaciones interdisciplinares: con la participación de profesores y profesoras de las diferentes disciplinas: Ciencias de la Naturaleza, Ciencias Jurídicas, Ciencias Sociales, Viencias de la Comunicación, Filosofía, etc.

- Seminarios.

- Publicaciones de las investigaciones y de otros estudios.

- Cursos monográficos.

- Conferencias.

- Biblioteca de Ciencias de las Religiones.

- $\quad$ Proyecto de Master en Ciencias de las Religiones.

- Revista (a partir de la consolidación de la Cátedra)

\section{Conclusión}

La Teología que empieza a desarrollarse a lo largo de toda la mitad del siglo XX, no solamente ha aportado nuevas claves de comprensión y planteamientos teológicos más acordes con el espíritu de la época; sino que ha suscitado también la multiplicación inicial de diversas instituciones eclesiales; así como la promoción y la renovación de la mayor parte de los centros de estudios teológicos en España.

En los veinte años siguientes a la celebración del CV.II tiene lugar, en la Iglesia Católica española, un florecimiento de instituciones docentes en los estudios teológicos, que aunque adoleciendo (en el ámbito de las facultades de teología) de una distribución geográfica no del todo acertada en el conjunto del territorio 
nacional, no cabe duda que su globalidad contribuyeron a la creación de nuevos ámbitos de estudio y de investigación; así como de diálogo, tanto intraeclesial como ecuménico, y a su proyección pastoral. A todo ello hay que añadir un esfuerzo de confrontación crítica con las perspectivas de una sociedad en un proceso de secularización creciente (M. Gesteria, 2010). Además de las ya existentes Universidad Pontificia de Comillas (UPC) fundada en 1891, y la Universidad Pontificia de Salamanca (UPS) restablecida en 1948, nace en 1967 la Facultad de Teología del Norte de España, con sede en Vitoria y Burgos; así como la Facultad de Teología de Deusto en el Marco de la Universidad de Deusto (UD) en Bilbao. En 1968 tiene lugar también la Facultad de Teología dentro de la fundación en el mismo año de la Universidad de Navarra (UN) en Pamplona. A comienzos de los años setenta es creada la Facultad de Teología de Cataluña con sede en Barcelona y en el sur de la península la Facultad de Teología de Granada regida por la Compañía de Jesús, pero abierta también a alumnos no jesuitas. A mediados de esa década de los setenta es erigida en Valencia desde la iniciativa diocesana una nueva Facultad de Teología que incorporaría a la que los dominicos tenía en dicha ciudad. Y, a finales ya de siglo en 1996 es creada la nueva Facultad de Teología de San Dámaso en Madrid.

Con el CV.II se intensifica entre los fieles -laicos y religiosos- un vivo interés por el estudio de la Teología y de otras ciencias sagradas, para enriquecer con ellas la propia vida cristiana, ser capaces de dar razón de la propia fe (cf. 1 Pe $3,15)$, ejercitar fructuosamente su apostolado propio y poder colaborar con los ministros sagrados en su específica misión (cf. can. 229 1-2).

En el período post-conciliar, mientras las Facultades eclesiásticas, que ya contaban con una larga tradición, se han conformado a las disposiciones de la Constitución Apostólica Sapientia Christiana (SC) (1979), ha ido asumiendo una creciente importancia en la Iglesia la necesidad de velar por una adecuada formación de los fieles laicos, mediante modalidades específicas.

Entre las iniciativas creadas para satisfacer tal exigencia se incluyen los Institutos Superiores de Ciencias Religiosas (ISCR). Su configuración jurídico-académica ha sido delineada por dos Documentos, emanados por la Congregación para la Educación Católica: la Nota illustrativa del 10 de abril de 1986 y la Normativa per l'Istituto di Scienze Religiose del 12 de mayo de 1987.

El estudio de la Teología y el estudio de las Ciencias Religiosas se articulan en dos itinerarios diferentes, que se distinguen sobre todo por la naturaleza de la enseñanza y por los currículos formativos que ambos proponen. 
El itinerario de estudio ofrecido por los Centros académicos eclesiásticos -como son las Facultades de Teología y los Institutos a ellas incorporados, agregados y afiliados- tiene el objetivo de asegurar al estudiante un conocimiento completo y orgánico de toda la Teología; esto se pide, en manera particular, a los que se preparan al sacerdocio. Además, dicho itinerario se propone profundizar de modo exhaustivo en las distintas áreas de especialización de la Teología, adquirir el necesario uso del método científico específico de esta disciplina, y también elaborar una contribución científica original.

Además de los ISCR, hay que destacar la creación de otros Institutos como el Instituto Superior de Pastoral (ISP) en Madrid dependiente de la UPS y el Instituto Superior de Ciencias Morales (ISCM) agregado a la UPC.

Sin embargo, a nivel de los centros universitarios estatales, siguió manteniéndose en España la exclusión laicista de la teología respecto a las diversas ciencias humanas (en especial la filosofía y las ciencias antropológicas en su diversas vertientes), impidiendo así un diálogo que podría ser iluminador para la sociedad: tanto en su vertiente o dimensión civil como eclesial. Diálogo interfacultativo (con la teología) que sólo se mantiene de hecho en los centros universitarios vinculados a la Iglesia Católica: como en las Universidades Pontificias de Comillas y de Salamanca, así como en la de Deusto y Navarra. Mientras brilla por su ausencia en los centros universitarios de titularidad estatal. (Gesteira, 2010).

Es en la década de los 90 del siglo XX y especialmente en la primera década de este siglo XXI cuando la teología está teniendo un nuevo reencuentro con las Universidades públicas Españolas, abriéndose en ellas, cauces para una nueva presencia de la teología en su seno: por ejemplo, en la UC3M existe la Cátedra de Teología y Ciencias de la Religión “Ignacio Ellacuría”. La UG en el año 2011, creó una Cátedra de Teología en colaboración con la Facultad de Teología S.J. La UM, ofrece desde el curso universitario 2009-2010, un Máster y un Programa de Doctorado en Teología desde el convenio de colaboración de la universidad con el ITM. Y, por último, la UV desarrolla desde el año 2000, la Cátedra de las tres religiones.

También a finales del siglo XX y principios del XXI surgen centros de estudios teológicos de otras confecciones cristianas. La participación de estos centros universitarios regidos por otras confecciones cristianas, se ha echado en falta durante todo este siglo $X X$ en España ya que posiblemente hubiera contribuido a elevar el nivel del diálogo ecuménico y a profundizar en las cuestiones teológicas.

La Teología cristiana-católica es un patrimonio universal que no ha de ser recluido en los límites de la comunidad religiosa católica como ha venido sucediendo hasta ahora. Ya, que es, y ha sido, una realización cultural de primera magnitud 
en la historia pasada y actual, con una influencia nada despreciable en millones de personas. En ella están presentes insospechadas virtualidades para entender la vida, el mundo, la historia, las relaciones en el ámbito privado y en el social.

Por ello, parece razonable que la Teología forme parte del mundo académico de las universidades públicas españolas, de manera que permita un diálogo interdisciplinario, desde el rigor que debe caracterizar el saber académico universitario, con el objetivo de que la Teología vuelva a estar en el lugar que nunca debió dejar de ocupar: el ámbito de reflexión académica y civil. De aquí, el planteamiento de que la Universidad pública incluya a la Teología cristiana-católica como parte de sus titulaciones oficiales.

Esta propuesta está posibilitada por los vigentes Acuerdos de 1979 entre el Estado Español y la Santa Sede, para el caso de las voces discrepantes de que se trata de un planteamiento confesional. El planteamiento confesional hoy en día está solventado desde el citado Acuerdo que permite y exige la implicación concertada de ambas partes Universidad e Iglesia. El principio de libertad religiosa y de que ninguna confesión tendrá carácter estatal viene marcado por el artículo 16 de la Constitución Española de 1978 que conduce a la aconfesionalidad del Estado. Aunque los poderes públicos según recoge dicho artículo tendrán en cuenta las creencias religiosas de la sociedad española y mantendrán las consiguientes relaciones de cooperación con la Iglesia católica y las demás confesiones. Lo que quiere decir que el Estado no toma partido ante las diferentes formas religiosas, ni se pronuncia sobre su veracidad, sino que asume la responsabilidad de ser garante y promotor de esa libertad.

Si es verdad, que la fórmula académica no viene regulada, por lo que da lugar a que su presencia sea como aula, cátedra, facultad o instituto teológico. Lógicamente la fórmula de facultad o instituto de teología, sería la más completa y ofrecería más posibilidades de estudio e investigación. Fórmula que existen en países europeos y que desde esta perspectiva supondría la plena integración de la Universidad pública española al proyecto de Bolonia.

\section{Referencias Bibliográficas.}

Aguilar, S. (2013). La jerarquía católica española en perspectiva comparada. La confrontación política entre la Iglesia y el Gobierno socialista a comienzos del siglo XXI. Revista Internacional de Sociología, 71 (2), 261-280.

Andres, M. (1980). Facultades de Teología, planes de estudio y proyecto de hombre. Scripta Theologica 12 (1), 161-169. 
Andrés, Melquiades. (1976). La supresión de la Facultad de Teología en las Universidades españolas (1852). Antológica Annua 18, 585-655.

Blázquez, R. (1978-79) La Teología en España y la Constitución. Sapientia Christiana SO 6-7, 263-276.

Cordovilla Pérez, A. (2012) Cristianismo, Teología y Universidad: ¿De la convivencia a la contraposición? Revista Proyección 247, 387-399.

Contreras Mazarío, J. Mª (2008). Marco jurídico del factor religioso en España. Documentos del Observatorio del Pluralismo Registro de España. Recuperado de http:// www.observatorioreligion.es

Frápolli Sanz, Ma J. (2012) ¿De qué hablan Dios y el César? El papel de los estudios de Teología en la Universidad Pública. Revista Proyección 247, 451-464.

García Hervás, D. (1996). Reconocimiento Civil de Títulos y Estudios Eclesiásticos. (Comentario al Real Decreto 3/1995, de 13 de enero*). IUS CANONICUM, XXXVI (71), 217-229.

Gesteira, M. (1971). Noticiario. XXX Semana Española de Teología. RET 31, 67-75.

Gesteira, M. (1984). La teología en España. En: B. Lauret-F.Refoulé. Iniciación a la práctica de la teología I, (340-356). Madrid, España: Cristiandad.

González de Cardedal, O. (1982). Situación actual de la teología española. En: Salmanticensis 29, 5-41.

González de Cardedal, O. (1980). Iglesia y política en la España de hoy. En: Salmanticensis $30,23-60$.

González Martín, R. (2016). Tesis Doctoral. Estudio de la presencia de la Teología en las Universidades públicas españolas en los albores del siglo XXI. Murcia, España: Universidad de Murcia.

González Martín, R; Parada Navas, JL. (2015). La presencia de la Teología Católica en las universidades públicas españolas en los albores del siglo XXI. En: Miscelánea Comillas. Revista de Ciencias Humanas y Sociales. 73 (143), 277-287.

González Montes, A. (2003). Presentación de Acuerdos Académicos y Pastorales entre Diócesis y Universidades. Madrid, España: Edice, 10.

Izquierdo, C. (2001). La reforma de los estudios eclesiásticos. En: Anuario de la Historia de la Iglesia. 10, 207-213.

Laboa Gallego, J. Ma. (2006). La recepción del Vaticano II en la Iglesia española. En Tejerina Arias, G. (coord.) Concilio Vaticano II, acontecimiento y recepción: estudios sobre el Vaticano II a los cuarenta años de su clausura (pp. 109-126). Salamanca, España: Universidad Pontificia de Salamanca, Servicio de Publicaciones. ISBN 84-7299-726-X.

Laboa Gallego, J. Ma. (2001). La Asamblea Conjunta. La Transición de la Iglesia española. En: XX Siglos. 12 (50) 4-33. 
Laboa Gallego, J. Ma. (1996). Vaticano II a treinta años del Concilio. Siglos, En: XX Siglos. 7 (27) 94.

Laboa Gallego, J. Ma. (1991). Relaciones Iglesia-Estado. En: Historia 16 (181) 129-140.

Laboa Gallego, J. Ma. (1992). Los Seminarios españoles a finales del siglo XIX. En: Miscelánea Comillas: Revista de Ciencias Humanas y Sociales. 50 (96-97) 31-44.

Laboa Gallego, J. Ma. (1985). Pensamiento teológico español del s. XX. En: Cuenta y razón 20, 151-157.

López Noguero, F. (2002). El análisis de contenido como método de investigación XXI. En: Revista de Educación 4, 167-179.

Martín de Santa Olalla Saludes, P. (2007). El concordato que nunca llegó a renovarse. En: Revista Historia del presente 10, 41-59.

Montero, F. (2007). Introducción: La Iglesia en el tardo franquismo o el "despegue" de la Iglesia. En: Revista Historia del presente 10, 3-6.

Nicolau, M. (1967). Reforma de las Facultades eclesiásticas. En: Ecclesia 27, 25-26.

Otaduy, J. (2001) Teología en la Universidad. Régimen legal de la enseñanza religiosa durante el Franquismo y la Transición. En: Anuario de Historia de la Iglesia 10, 75-94.

Palomares Montero, D., García Aracil, A., Castro Martínez, E. (2012). Misiones Actuales de la Universidades Públicas: Una Perspectiva Sociológica. En: ARBOR Ciencia, Pensamiento y Cultura. 188 (753) 171-192.

Pérez Tapias, J. A. (2012). Los usos de la razón en la Universidad: ¿también una razón teológica? En: Revista Proyección: Teología y mundo actual. 247, 401-432.

Rodríguez Duplá, L. (2000). El lugar de la Teología en la Universidad. Documentos del Instituto de Antropología y Ética. En: Boletín del Departamento de Pastoral Universitaria y Pastoral de la Cultura. Conferencia Episcopal Española. 1, 13-21.

Romera Oñate, L. (2013). La razón responsable y la Universidad. El lugar de la teología. En: Romera Oñate, L.; Rodríguez Duplá, L.; López Goñi, I.; La fe en la universidad, (9-24) Navarra, España: Instituto de Antropología y Ética. Grupo de investigación "Ciencia, razón y Fe" (CRYF), Universidad de Navarra. 